\title{
Study on the Innovation Practice of Digitized Higher Education
}

\author{
Yulan Zhao ${ }^{1, a}$ and Chunfeng Jiang ${ }^{2, \text { b * }}$ \\ 1,2Jilin Agricultural Science and Technology University, Jinlin China \\ allbird@126.com, bhero_jcf@126.com
}

Keywords: Digitization; Practice; Entrepreneurial education; Innovation education; Research

\begin{abstract}
The development of digitization and informatization is changing the concrete cultural transmission ways of people, which will surpass the current limitation of education, realize the sharing of educational resources across the time and space and give rise to significant educational reform.
\end{abstract}

\section{Introduction}

As the everlasting topic of social progress and human development, the innovation emphasizes the creation of talent training modes. In recent years, the creational education becomes the core topic of educational quality and the research papers of creational education emerge one after another. However, the educational theory and the educational practice get no practical development. The innovative higher education in China has serious "KFC" tendency in the research theories for a long time, which is always shown in the imitation or complete copying and considers nothing about the national elements of Chinese education; as to the exploration and practice, it doesn't refer to the innovation of inherent meaning but only the forms, busy with pasting new labels to various educational phenomena, for example, regarding the interest groups of students as the research type study, deeming the second major and the second class as the practical lesson and turning one or two Chinese lessons and college PE as the humanistic quality education. The aimless construction of different experiment places is definitely not the innovation education, which therefore can't actually strengthen the innovation ability of students. Here, the author hopes to talk about how to start to change the current situation through my practical experience of teaching in these years.

\section{Development of Digital Informatization}

Since 1990s when people were studying and discussing about the new changes, education and assistance brought by the development of digital informatization, at the turn of century, the state formally put forward the strategic decision-making education to take advantage of the digital model so as to improve the development and required the colleges and universities to take the lead in implementing it. In 2010, the State Council presented clearly in the published "the national development plan in the future ten years" to "pay much attention to the changes occurring in the IT education" and "further enhance the educational information level". In the recent 20 years, the schools make breakthrough in the digitization construction process and develop from the initial informatization to digitization and intelligentization. Up to now, the information technology colleges have begun to take shape and the basics of digitization have been preliminarily built, including the multi-media classroom, network laboratory and digital library. The digitization patterns alter the college education and the life of students.

Nowadays, nearly all the college students are the generation after 1990s, who are living in the knowledge and information barrier-free environment. They are familiar with the network, which has been an indispensable part of their life. Einstein once said "interest is the best teacher". According to this model, the colleges that have adopted the digitization can get twofold results with half the effort by sticking to the principle of taking students as the leadership, carrying out the reform and innovation of higher education in the digital environment, reforming the education in the digital process by utilizing the information technology teaching and improving students' abilities in 
communication, cooperation and innovation. The so-called educational reform and innovation shouldn't be the water without a source or a tree without roots, staying at the stage of the slogan coming first without creation.

\section{Adhere to Textbook Content to Improve Innovation Practice of Digitized Higher Education}

The hypertext is people's mode of thinking to handle with the information according to the network structure arrangement. If we dispose a book in the method of hypertext, the book will be different from the traditional documents. The items, sections and words are arranged together, forming some special relationship. The page number problem that we diligently pursue after doesn't matter anymore. We can begin reading at any time depending on our interest and need. The cognitive psychology considers that there is relevance of characteristics in human mind. As people tend to jump from one concept to another in the process of thinking and reading, the hypertext textbook organization conforms better to human's thinking habit. As to the processing of concrete materials, we can divide it into different units, including text, exercises, answers and improved part according to the requirements of teaching content and different teaching resources combining with the teaching characteristics, so that competent teachers can teach their familiar parts. Besides, as to the linear array traditional method of book replaced by the hypertext, it is easy for us to do it. The implementation of the individualized teaching is an important approach. We can make up an organic whole according to the students of different levels and their knowledge and knowledge enlargement. As there are huge level and individual difference between the students, the traditional textbooks can hardly satisfy the various needs of students of different levels. However, the multi-media electronic textbook can accomplish it easily only by setting related shortcut keys.

\section{Stick to Spatialization to Improve the Innovation Practice of Digitized Higher Education}

Students are losing patience with the teacher-oriented teaching method in knowledge impartation. The class should reflect the dominant role of students so as to develop their imagination, improve their innovation ability and enrich the multiple teaching forms. We can try to enhance students' ability in evolving and creating the problem situation, etc.

To Make Bold Attempts so as to Enrich the Exercise Opportunities for Students. The digitization and innovative education of the higher education practice shouldn't only be limited to the theory but also the solution to the relationship between the theory and practice. Why the developed countries can success in innovation and reforming education? Why there is still so much innovative talent training? One of the most important reasons is that the "have a try" idea is widely accepted by the westerners. The western temples accept the "attempt" idea of the primary school students while Chinese parents and teachers hardly say "have a try", which is the first difference between the oriental and occidental cultures. In our opinion, there is always failure if one does not try; this is the significant difference between the oriental and occidental educational ideas: studentoriented in western countries and teacher-oriented in China. For example, in Canada, the students are told that the community is a great place for "attempt", the school is a small foundation for "attempt" and the classroom is a miniature forward for "attempt". As to the principal mode of infusion education in China, students have been used to the long-term passive situation of "you say and I listen". Therefore, the educational effects are inevitably different. If a person wants to learn, added with perseverance, what shouldn't do, what can't do and what can't do in this way? The willingness of being prior to carry and try is the source of imagination and the expressional innovation ability is the symbol of anger and the sign of confidence. Therefore, we should create an atmosphere of encouraging students to try boldly and bring forward new innovation embryo.

Focus on Cultivation of "Comprehending by Analogy" Thought and Actively Enhance the Guidance in Different Occasions. Edward de Bono profoundly pointed out in his book that: "Education teaches people knowledge for there is nothing can be taught. However, the knowledge can't replace the thought, just as the thought to the knowledge." In the most practical condition, the knowledge is never complete. As a result, we should transfer the knowledge into thought, in which 
way the knowledge can be developed in the learning process. Edward de Bono gives us the enlightenment: first, to cultivate students' active thought so that the students can be practical with creativity and constructivity, abandoning the traditional passive thought. Second, to lead students to grasp the relationship between the basic knowledge and thinking quality. The basic knowledge is thought. The lack of correlation among the knowledge will result in the failure of thinking. However, too complete knowledge makes students give up thinking. In our education, our brain is just used up in learning the knowledge at university time. Actually, compared to the way of thinking, the knowledge is easy to be imparted. However, the knowledge acquisition can't replace the psychic existence. Both of them are indispensable. At last, to realize the importance of affective thinking. We have been focusing on the cultivation of students' ability and logical thinking for a long time. As a fact, the intuition is of the same importance, undertaking a half ideological work. Therefore, in order to improve students' ability of thinking, the teachers should train their acquaintance consciously. As to the concrete implement scheme, we should pay attention to the following questions: firstly, "delivery". The teacher doesn't need to say too much or complicated. Otherwise, the cramming teaching method will be formed. The teacher should keep in mind that the so-called "elevator" is just to guide the students to have their unique understanding for more efficient "drawing inferences". If too many students are confused, the "drawing inferences" effect will be poor and the teacher will get back to the "teacher dominant" teaching mode. Secondly, the ultimate meaning of "drawing inferences" is the ability to acquire new knowledge with old one. Therefore, this process is of great difficulty, taking much time. The teachers should make thorough psychological preparation. Thirdly, "drawing inferences" can utilize and improve the practice. The teacher seriously lays stress on the research for students, finds out the disadvantages and offers guidance on this foundation. Only in this way, can the students get more interested in study.

To Set Problem Situation and Offer Opportunity for Students so as to Show Their Dominant Role. Students' consciousness must be shown in the interaction process in class. The loyalty and love for the teacher education is the source of teachers' emotion and motivation. If the teacher can keep passion in the teaching process, persuade students, motivate their learning interest and encourage them to break the routine for self-invention and different way of thinking, which can develop students' ability of overall planning, independence and creativity. To achieve this, we should set the problem situation of the teachers and let the students find their own way of thinking after immersive. Innovation is the fundamental standard for talents at this era. We can't continue the natural way of old thought and concept. The innovation ability is the foundation for students. The innovation of students is reflected in the limitless thirst for knowledge, great curiosity and expertness in operation.

Persist in Expanding the Teaching Space in Order to Improve the Innovation Practice of Digitized Higher Education. The old classroom teaching inside the classroom has been out of date. If we can't improve the educational classroom environment with the times passing by, the final result will be that the students get tired and even leave. As we are in the era of unceasingly developing science and technology, the best way is the take full advantage of the modern tools for new teaching materials in the college education. Of course, the author doesn't require each teacher to set up a website, blog or carry out the distance education, which are needless. However, the author hopes that the teachers can search enough teaching materials to help students walk out of the classroom and acquire more knowledge in wider space. In practice, based on the intelligent network environment, we can build the educational environment of collaborative learning. The main task of such new educational environment and campus network is to supply intelligent learning environment, knowledge source, wide horizon, knowledge and viewpoint so as to promote people's imagination, satisfy different individual requirement and cultivate the independent thinking consciousness, which can be activated and produce spark. The new learning environment is suitable for the young, vivacious and curious natural instinct. To take advantage of the network collaborative learning environment can encourage the students boldly get rid of the constraint of classroom, carry out communication through the network and get more time and space for rest. Various network learning, including the graph, voice frequency, image, flash and video, etc. offers 
rich resources for students so that the students can get another platform for self-presentation and improve greatly their confidence and team spirit, which are necessary for creative thinking. We should realize that the educational innovation that we are going to experience is actually a reform from industrial society to the information society and education and a knowledge society of new concept transformation. In this thesis, as the statement of the author, some basic ideas may have some mistakes and some thoughts and methods may be imperfect and not comprehensive, requiring more profound discussion, theory and practice. We are faced with an arduous task. The creational education and various educational elements are needed to enhance the interaction between the theory and practice as well as the coordination between the internal and external aspects of the whole society. We expect more people to join in the discussion to promote and perfect together the higher education mode in China.

\section{Conclusion}

In conclusion, as the digitized higher education is an important item in the practice process of creational education, we should abandon the traditional educational thought and educational mode, take advantage of the new educational resources in the modern society and reform multiple teaching links, such as the teaching mode, teaching atmosphere and the teaching content so as to gradually overturn the original education situation, implement the educational innovation practice, perfect the creative teaching through the network technique and digitization science and promote the flourishing development of higher education.

\section{Acknowledgements}

Ministry of Education CAXC-13A-20; Education Science Planning in Jilin province GH14333; Jilin Agricultural Science and Technology University 2015X096; Jilin Agricultural Science and Technology University JGYB008.

\section{References}

[1] J.P Kang: Liaoning Education Research, (2007) No.8, p.305.

[2] X.J. Guo: Study on Creational Education Mode in Colleges against the Background of Knowledge Economy (MS., China University of Geosciences, China 2012), p.28.

[3] C.F. Hai: Gansu Gaoshi Journal, 2012.

[4] J.Q. Chang: Journal of Heilongjiang Institute of Education, 2011.

[5] J.H. Xu, Y. Wang, P. Zhang: Journal of Contemporary Educational Practice and Teaching Tesearch (Electronic Version), 2015.

[6] Z.H. Zhu: Building an Innovation-originated Nation and the Reform and Development of Chinese Higher Education- International Forum of Higher Education, 2013.

[7] N. Zhou, C.J. Fu: Oriental Education, 2014.

[8] W.H. Hou: Innovation and Entrepreneurial Education Course for Undergraduates(Science Press, China 2012).

[9] Innovation and Entrepreneurial Management, Key Research Institute in University(Tsinghua University Press, China 2012). 